\section{The cataract surgery access debate: why variation may be a good thing}

S Coronini-Cronberg ${ }^{1,2}$
Eye (2016) 30, 331-332; doi:10.1038/eye.2015.272; published online 22 January 2016

Cataract surgery carries the accolade of being one-if not the-most common elective procedure carried out by the National Health Service (NHS) in England each year ${ }^{1}$ Over the decade 2002 and 2003 to 2011 and 2012, the rate of NHS provision increased annually by $1.8 \% .^{2}$ In absolute terms, the NHS funded 637 episodes per 100000 population in 2004, though the true figure is likely to be substantially higher if privately funded surgery had been included in these estimates. ${ }^{3}$

This increase broadly coincided with reduced median waiting times, which dropped from $>200$ days in 1998 to <75 days in 2007, and by 2011-12 this was 59 days from specialist assessment to treatment. ${ }^{4,5}$ Reassuringly, offering more surgery appeared to result in superior access equity, with an inverse relationship between area deprivation and cataract surgery waiting times emerging. ${ }^{4}$

In 2009, it was announced that the NHS would make $£ 20$ billion savings between 2011 and 2012 and 2014 and 2015. ${ }^{6}$ These savings were to be recurrent, and found through service efficiencies, including reducing reliance on overused interventions. ${ }^{6,7}$ Although cataract surgery is, in absolute terms, considered clinically very effective, questions are increasingly being raised about whether it is being over- or inappropriately used, particularly in mild cases where the risks of surgery may outweigh any potential health benefits. 3,8,9

For example, at a population level, the risk of visual loss among patients with better presurgery visual acuity (VA) is not inconsiderable: $6.9 \%$ of patients with a baseline VA of $\leq 6 / 6$ Snellen (approximation of $\leq 0.00 \log \mathrm{MAR}$ ) and $5.6 \%$ of those with a VA of $\leq 6 / 9$ Snellen (approximation of $\leq 0.18 \log \mathrm{MAR}$ ) are left with poorer vision following cataract removal. ${ }^{10}$ This is more conservative than an earlier study which found the majority $(64.3 \%)$ of patients with pre- operative acuities of $\leq 6 / 7.5$ Snellen had the same or worse vision following surgery. ${ }^{11}$

The real challenge, then, is ensuring that appropriate candidates for surgery receive it in a timely manner, while inappropriate ones are excluded or deferred. Improving the quality and appropriateness of referrals to specialist treatment could both improve patient experience and reduce costs by reducing unnecessary consultations, as well as widening access to and speed of treatment for those that need it. ${ }^{12}$

Quite apart from the harm operating on the wrong patients represents, there could also be a considerable opportunity cost. In other words, the NHS could be making more effective use of its shrinking resources by avoiding overuse in cataract surgery and putting resources towards other health purchasing, ${ }^{9}$ such as targeting its spending at relatively more effective surgeries.

Indeed, a 2011 survey of Primary Care Trusts (PCTs) found that half (47\%) had current policies in place to manage access to cataract surgery. ${ }^{13}$ The financial year 2011-12, saw a statistically significant drop of $4.8 \%$ in the overall rate of cataract surgery undertaken by the NHS, a decline that coincided with the first year of financial austerity. ${ }^{2}$

The pattern, though, was varied among commissioning organisations: while a third $(30.5 \%)$ of PCTs had reduced rates of cataract surgery, about one-sixth (13.2\%) showed increases. ${ }^{2}$ Reassuringly, though, there were no discernable differences in surgery rates between more or less affluent areas, suggesting inequity is still not a particular concern. ${ }^{2}$ What the data cannot currently tell is whether the observed reductions coincided with fewer inappropriate surgeries.

There is a growing public perception that a 'postcode lottery' is emerging, with patients being unfairly denied access to cataract surgery. ${ }^{14,15}$ Assuring commissioners, clinicians and the public that any reductions in procedure rates actually coincide with reduced episodes of inappropriate
${ }^{1}$ Department of Primary Care and Public Health, School of Public Health, Faculty of Medicine, Imperial College London, London, UK

${ }^{2}$ Corporate Centre Medical, Bupa, London, UK

Correspondence:

$S$ Coronini-Cronberg, Department of Primary Care and Public Health, Imperial College London, Reynolds Building, St. Dunstan's Road, London W6 6RP, UK

Tel: +44 2075943362. E-mail: s.coronini-cronberg @imperial.ac.uk 
care-and do not just delay necessary surgeries or restrict access to appropriate care-will necessitate much more sophisticated utilisation data that measures both volumes and appropriateness of procedures backed by clear public health messaging. For now, the lack of validated tools that objectively measure cataract-induced visual impairment and therefore the appropriateness of surgery remain to be significant weakness and the commissioning guidance calls for more urgent research into this area. ${ }^{16}$

The recent NHS reforms have focussed on devolving decision-making. A risk of decentralising healthcare purchasing is that instead of having a uniform national standard apply differing local commissioning priorities can affect access to health services. In April 2013, the 151 PCTs were replaced by 211 smaller Clinical Commissioning Groups (CCGs), thereby running the risk that any geographical variation may be exacerbated further.

Evidence-based commissioning guidance, such as this new cataract services guide, can provide an important step towards national consistency by providing a useful blueprint of how to plan and buy cataract surgery. ${ }^{16}$ That said, it is important to remember that despite being accredited by the National Institute for Health and Care Excellence (NICE), these recommendations are not binding. Commissioners may-legitimately-choose to prioritise spending their constrained budgets other areas of healthcare, according to the needs of their local resident population. As data on CCG activities become available, more research will be needed to monitor the consistency of their commissioning decisions. ${ }^{2}$

The debate we are having around cataract surgery is not unique. Instead, what is urgently called for is a much wider societal discourse around the merits of central versus local health purchasing and, in particular, an acceptance that pursuing the latter is going to result in geographical variation of services. This in itself need not be a bad thing if more overall health gain is purchased as a result of commissioning strategies focussed on meeting residents' health needs: balancing the tension between local health needs and finances will likely necessitate a relative prioritisation of procedures, which may mean even clinically effective interventions are de-prioritised or even decommissioned. And that could conceivably include cataract surgery.

\section{Conflict of interest}

S Coronini-Cronberg is a Consultant in Public Health, and also Head of Clinical and Cost Effectiveness at Bupa, an International Healthcare Group that may fund or provide cataract surgery.

\section{Author contributions}

The manuscript represents original, valid work and neither this opinion paper nor a substantially similar one, has been previously submitted to any other publications. The views expressed in this article are those of the author and not necessarily of either Bupa or Imperial College, London.

\section{References}

1 Black N, Browne J, van der Meulen J, Jamieson L, Copley L, Lewsey J. Is there overutilisation of cataract surgery in England? Br J Ophthalmol 2009; 93: 13-17.

2 Coronini-Cronberg S, Bixby H, Laverty A, Wachter R, Millett C. English National Health Service's savings plan may have helped reduce the use of three 'low-value' procedures. Health Aff (Millwood) 2015; 34: 381-338.

3 Keenan T, Rosen P, Yeates D, Goldacre M. Time trends and geographical variation in cataract surgery rates in England: study of surgical workload. Br J Ophthalmol 2007; 91: 901-904.

4 Cooper Z, McGuire A, Jones S, Le Grand J, Titmuss R. Equity, waiting times, and NHS reforms: retrospective study. BMJ 2009; 339: 673-675.

5 House of Commons (HC) Hansard. Available at http:/ / www. publications.parliament.uk/pa/cm201314/cmhansrd/ cm130711/text/130711w0001.htm. 2013.

6 Morse A. Progress Making NHS Eficiency Savings. National Audit Office: London, UK, 2012.

7 Garner S, Littlejohns P. Disinvestment from low value clinical interventions: NICEly done? BMJ 2011; 343: d4519.

8 Malhotra N, Jacobsen B. Save to Invest: Developing Criteriabased Commissioning for planned health care in London. London Health Observatory: London, UK, 2007.

9 Audit Commission. Audit Commission Health Briefing: Reducing Spending on Low Clinical Value Treatments. TSO (The Stationery Office): London, UK, 2011.

10 Day A, Donachie P, Sparrow J, Johnston R. The Royal College of Opthalmologists' National Opthalmology Database study of cataract surgery: report 1 , visual outcomes and complications. Eye 2015; 29: 552-560.

11 Jaycock P, Johnston RL, Taylor H, Adams M, Tole DM, Galloway $\mathrm{P}$ et al. The Cataract National Dataset electronic multi-centre audit of 55567 operations: updating the benchmark standards of care in the United Kingdom and internationally. Eye 2009; 23: 38-49.

12 Naylor C, Imison C, Addicott R, Buck D, Goodwin N, Harrison $\mathrm{T}$ et al. TranSforming Our Health Care System: Ten Priorities for Commissioners. The King's Fund: London, UK, 2013.

13 Coronini-Cronberg S, Lee H, Darzi A, Smith P. Evaluation of clinical threshold policies for catarct surgery among English commissioners. J Health Serv Res Policy 2012; 17: 241-247.

14 The Patients Association. The Waiting Game: The Results of Patients Association Research Into Elective Surgical Procedures. The Patients Association: London, UK, 2012.

15 Royal National Institute of Blind People (RNIB). Saving Money, Losing Sight. RNIB: London, UK, 2013.

16 Royal College of Opthalmologists. CommissIoning Guide: Cataract Services. Royal College of Opthalmologists: London, UK, 2015. 